Textos 



\title{
Problemas causados
}

\section{por Gutenberg: a explosão da informação nos primórdios da Europa moderna}

\author{
PETER BURKE
}

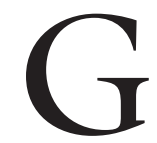

UTEnberg e a imprensa de há muito vêm sendo celebrados. Desde o século XVI a máquina impressora é descrita como tendo literalmente marcado uma época. Tem sido vista como o símbolo de uma nova era, associada com freqüência à pólvora (outra invenção atribuída aos alemães) e às vezes também à bússola. Francis Bacon vinculava a imprensa ao progresso do conhecimento (o advancement of learning, segundo suas palavras), ao ideal da pansofia e ao sonho utópico de anular as conseqüências do pecado original.

A idéia de comemorar centenários com celebrações festivas era extremamente rara antes de 1617, ano em que os protestantes alemães celebraram o centenário da afixação em Wittenberg das famosas teses de Martinho Lutero. Mesmo assim, uma celebração semelhante aconteceu em 1640, ano que se acreditava marcar o bicentenário da invenção de Gutenberg. Esse festival, um jubilaeum typographicum celebrado em Leipzig, coincidiu com a publicação de dois estudos da história da imprensa, um de Mark Boxhorn e o outro de Bernhard von Mallinkrot, ambos enaltecendo a nova invenção. Muitas descrições subseqüentes da imprensa adotaram um tom semelhante (1).

Neste artigo, porém, minha abordagem será menos triunfalista. Tradicionalmente a imprensa de tipos móveis é vista como a solução de um problema, como um modo de garantir o suprimento de textos para atender sua crescente demanda no final da Idade Média, uma época em que o número de homens e mulheres alfabetizados estava aumentando. Todavia, essa não é a única perspectiva possível. No que segue - sem intenção alguma de negar o feito de Gutenberg, ou mesmo o dos chineses ou coreanos, que também haviam inventado formas de imprensa - gostaria de examinar algumas das conseqüências imprevistas da invenção, seus efeitos colaterais, os problemas que com ela surgiram.

Parece inevitável que nas atividades humanas todas as soluções de um problema mais cedo ou mais tarde acabem gerando outros problemas. Como sugeriu o geógrafo sueco Torsten Hägerstrand, o processo de inovação sempre 
tem um aspecto positivo e um aspecto negativo, um "lado destrutivo" e um lado criativo. O lado destrutivo ele denomina "denovação" em oposição à inovação (2). No caso da Revolução Industrial, por exemplo, basta pensar nos operadores de teares manuais que não conseguiam competir com a nova tecnologia, bem como na mão-de-obra infantil nas novas fábricas.

As descrições "triunfalistas" da nova invenção com as quais comecei este artigo foram contrabalançadas desde o início pelo que poderíamos chamar de narrativas "catastrofistas". A imprensa foi descrita pelo humanista francês Guillaume Fichet - que introduziu a máquina impressora em Paris - como o "cavalo de Tróia" (3). Diferentes grupos sociais levantaram diferentes críticas ao novo instrumento. Por exemplo, os copistas os e os "papeleiros" (que vendiam livros manuscritos) e os cantores contadores de histórias profissionais, todos temiam - como acontecera com os operadores de teares manuais na Revolução Industrial - que a imprensa os privaria de seu meio de vida.

Os eclesiásticos, por sua vez, temiam que a imprensa estimulasse leigos comuns a estudar textos religiosos por conta própria em vez de acatar o que lhes dissessem as autoridades (4). Tinham razão. No século XVI, na Itália por exemplo, sapateiros, tintureiros, pedreiros e donas-de-casa, todos reivindicavam o direito de interpretar as escrituras (5). O Índice Católico dos Livros Proibidos, criado depois do Concílio de Trento, foi uma tentativa de lidar com esse problema. Outra possibilidade era, naturalmente, as igrejas adotarem o novo meio na tentativa de usá-lo para seus próprios objetivos. Na Suécia protestante, por exemplo, no século XVII a Igreja organizou uma campanha de alfabetização - talvez a primeira dessa natureza na história moderna - que visava a estimular a leitura da Bíblia (6). Todavia, tal solução por sua vez gerava novos problemas. A publicação, do século XVII em diante, de livros baratos como Fortunatus e Ulspegel mostra que, depois de aprender a ler, as pessoas comuns não se restringiam à leitura da Bíblia, como desejaria o clero.

Na década de 1620 às preocupações religiosas somaram-se preocupações políticas. Ludovico Zuccolo, um escritor italiano, evocava a imagem das barbearias cheias de gente comum discutindo as medidas dos governantes. Essas preocupações refletiam em parte uma reação ao surgimento nessa época de jornais impressos, conduzindo a um debate resumido no tratado Vom Gebrauch und Missbrauch der Zeitungen (1700), de Johann Peter von Ledwig. Governos autoritários criticados pela imprensa enfrentavam um dilema muito semelhante ao das igrejas. Se não respondessem às críticas, poderiam dar a impressão de que não tinham argumentos a apresentar. Se, por outro lado, respondessem, ao fazê-lo estimulavam a própria liberdade de julgamento político que desaprovavam. É natural então que o inglês Sir Roger L'Estrange, o principal censor da imprensa depois da restauração de Carlos II, se perguntasse "se a invenção da tipografia não trouxera mais malefícios do que vantagens para o mundo cristão" (7). 
Os estudiosos, ou mais genericamente os que buscassem o conhecimento, também enfrentavam problemas. Observemos deste ponto de vista a assimchamada "explosão" da informação - uma metáfora desconfortável que faz lembrar a pólvora - subseqüente à invenção da imprensa. A informação se alastrou "em quantidades nunca vistas e numa velocidade inaudita" (8). Alguns estudiosos logo notaram as desvantagens do novo sistema. O astrônomo humanista Johann Regiomontanus observou, por volta de 1464, que os tipógrafos negligentes multiplicariam os erros. Outro humanista, Niccolò Perotti, propôs em 1470 um projeto defendendo a censura erudita. Mais sério ainda era o problema da preservação da informação e, ligado a isso, o da seleção e crítica de livros e autores. Em outras palavras, a nova invenção produziu uma necessidade de novos métodos de gerenciamento da informação.

$\mathrm{Na}$ alta Idade Média o problema fora a escassez, a falta de livros. No século XVI o problema era o da superfluidade. Antonfrancesco Doni, escritor italiano, em 1550 já se queixava da existência de "tantos livros que não temos tempo para sequer ler os títulos". Livros eram uma "floresta" na qual os leitores poderiam se perder, segundo Jean Calvin (9). Eram um “oceano" pelo qual os leitores tinham de navegar, ou uma "inundação" de material impresso em meio a qual era difícil não se afogar (10). As metáforas de florestas e oceanos eram topoi, naturalmente, mas como topoi em geral também expressavam a experiência vivida. O bibliotecário francês Adrien Baillet temia que a multiplicação de livros trouxesse consigo uma nova época de barbárie. "On a sujet d'appréhender que la multitude de livres qui augmentent tous les jours d'une manière prodigieuse, ne fasse tomber les siècles suivants dans une état aussi fâcheux qui étoit celuy où les barbares avoit jeté les précédents” (11).

Até mesmo Conrad Gesner, o humanista suíço que cunhou a expressão "a ordem dos livros" ( ordo librorum), recentemente adotada por Roger Chartier como título de um de seus trabalhos, também se queixava da "multidão confusa e irritante de livros" (confusa et noxia illa librorum multitudo). Mais que uma ordem de livros, o que alguns contemporâneos percebiam era uma "desordem de livros" que precisava ser controlada. Este é certamente um problema com que nós também estamos brigando atualmente, nos primórdios da mídia eletrônica. Por essa razão o estudioso alemão Michael Giesecke descreveu seu estudo sobre a imprensa germânica dos séculos XV e XVI como um "Fallstudie über die Durchesetzung neuer Informations- und Kommunikationstechnologien". Giesecke faz uma descrição voltada para o sistema daquilo que chama "Das Typographeum als Informationsystem".

Neste artigo, por outro lado, gostaria de apresentar uma descrição mais voltada para o agente em termos de uma seqüência de problemas e soluções, embora admitindo que essas soluções muitas vezes se tornam ações humanas institucionalizadas que se solidificam em estruturas sociais. 
Vale a pena repetir alguns dados estatísticos muito conhecidos para lembrar a escala das mudanças que aconteceram no início das comunicações modernas. Por volta do ano de 1500 havia impressoras em mais de 250 centros europeus e elas já haviam produzido cerca de 27 mil edições. Fazendo uma estimativa conservadora de 500 exemplares por edição, haveria então algo em torno de 13 milhões de livros em circulação no ano de 1500 numa Europa de 100 milhões de habitantes (excluindo-se o mundo ortodoxo, que escrevia em grego ou russo ou eslavo eclesiástico). Já para o período entre 1500 e 1750, foram publicados na Europa tantos volumes cujos totais os estudiosos da história do livro não conseguem ou não querem calcular (com base no índice de produção do século XV o total estaria ao redor de 130 milhões, mas de fato o índice de produção aumentou dramaticamente).

A multiplicação dos livros criou imediatamente um problema para um grupo profissional, o dos bibliotecários, embora seja óbvio que eles se tornaram ainda mais indispensáveis. Em 1745 uma das principais bibliotecas européias, a do Vaticano, abrigava apenas 2.500 volumes. No início do século XVII a Bodleian Library de Oxford tinha 8.700 títulos, e a biblioteca imperial de Viena, 10 mil. Em meados do mesmo século a biblioteca de Wolfenbüttel abrigava 28 mil volumes, enquanto a Ambrosiana de Milão tinha 46 mil (sem contar os manuscritos). Em meados do século XVIII um cidadão de Londres, Sir Hans Sloane, havia acumulado 50 mil volumes (que depois formariam o núcleo do que é hoje a British Library). Foi preciso construir prédios enormes para abrigar tantos livros (Fischer von Erlach's Hofbibliothek em Viena, por exemplo), os quais, por sua vez, exigiram financiamentos.

A existência de livros impressos facilitou mais do que nunca a tarefa de encontrar informações - desde que antes se encontrasse o livro certo. Para isso, foi preciso compilar catálogos para grandes bibliotecas, particulares ou públicas. Baillet compilou um catálogo em 32 volumes para seu patrão, o magistrado Lamoignon, um trabalho que ajuda a explicar seu desabafo, como já mencionado, sobre o advento de uma época de barbárie. A compilação desses catálogos criou o problema de como organizá-los. Por assunto ou por autor numa lista em ordem alfabética? Se por assunto, segundo o tradicional currículo das universidades ou de um modo novo e mais adequado às novas descobertas (um problema que, entre outros, preocupava Leibniz)?

Também existia o problema do acesso. Como poderiam os leitores descobrir que livros estavam disponíveis numa determinada biblioteca? Como particularmente poderiam os leitores de outras cidades ou países saber que valeria a pena empreender uma viagem para uma determinada biblioteca em busca de um determinado livro? Imprimiram-se alguns catálogos, como o da Bodleian Library de Oxford do início do século XVII. Uma alternativa ao catálogo de determinada biblioteca era uma bibliografia impressa, o catálogo de uma biblio- 
teca ideal ou da "biblioteca sem paredes" (como a chama Chartier, adaptando uma expressão de André Malraux) (12).

O humanista suíço Conrad Gessner (1516-65), por exemplo, um verdadeiro polímeta, que escreveu sobre zoologia, botânica, química, geologia e lingüística, foi também o autor da enorme Bibliotheca Universalis (1545-55), uma tentativa de compilar uma bibliografia completa de obras eruditas organizada por autor e por assunto (13). Vale a pena refletir por um instante sobre os problemas práticos de uma iniciativa como essa. Imagine Gessner viajando para visitar bibliotecas na Itália e em outros países, fazendo suas volumosas anotações, utilizando inúmeras penas de ave, que a toda hora precisavam ser aguçadas, e tendo de manter suas anotações em ordem (talvez, como fariam futuros pesquisadores, em tiras de papel ou no verso de cartas de baralho).

Do ponto de vista do leitor, nem sempre era fácil encontrar informações bibliográficas num repositório tão vasto como o de Gessner. Assim, bibliografias gerais foram sucedidas por outras mais específicas e fáceis de manusear, incluindo-se bibliografias nacionais como a Bibliothèque Françoise de La Croix du Maine (1584) e bibliografias organizadas por assunto no campo de teologia, direito, medicina, história e assim por diante, como a Bibliotheca Historica de Boldanus (1620). Algumas bibliografias procuravam ser abrangentes, outras eram deliberadamente seletivas.Uma longa série de Bibliothecae Selectae ou Bibliothèques Choisies (desde o jesuíta Possevino no século XVII até o protestante Formey no século XVIII), às vezes na forma de orientação para quem desejasse formar uma biblioteca, ajudava os leitores a fazerem sua escolha entre livros concorrentes (14). O Polímeta de Daniel Morhof (durante um certo tempo bibliotecário de Kiel) e descrições semelhantes de historia literária ofereciam não exatamente uma história da literatura no sentido moderno, mas um guia para o mundo dos livros e suas instituições - em outras palavras, informações sobre informações.

Como o aparecimento de bibliografias em meados do século XVI, o aparecimento de resenhas cem anos mais tarde foi uma resposta a um problema que se tornara cada vez mais agudo, o problema do discernimento, como o chamava Baillet, em outras palavras o de discernir entre os bons e os maus livros. As resenhas apareciam em revistas eruditas, que foram em parte criadas por essa razão: a Philosophical Transactions da Sociedade Real de Londres e o Journal des Savants de Paris na década de 1660, as Acta Erudictorum de Leipzig e as Nouvelles de la Republique des Lettres de Amsterdã na década de 1680, e assim por diante. O título "Notícias da república das letras" explica muito bem a finalidade dessas revistas. Apareciam a cada um ou dois meses trazendo informações acerca de novos livros, incluindo-se resumos e às vezes apreciações críticas. Como as bibliografias, algumas dessas revistas eram especializadas, entre elas a Dänische, a Pölnische e a Schwesdische Bibliothek. 


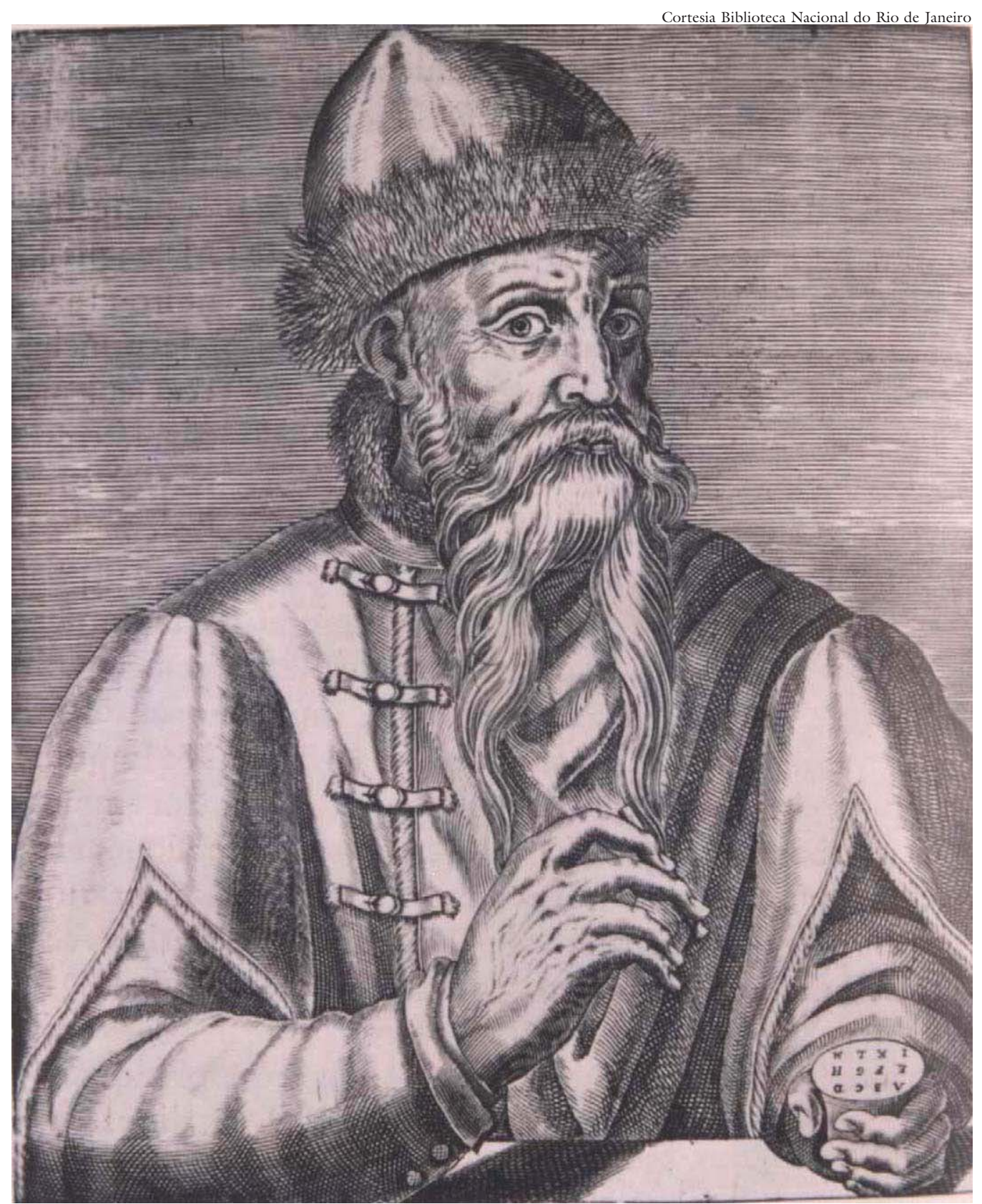

Retrato conjetural de Gutenberg, datando do século XVI (Do livro de McMurtrie, The book.)

Essa solução, por sua vez, gerou o problema da localização das resenhas, ou mesmo de achar as revistas, que eram publicadas em tantas cidades diversas da Europa e às vezes duravam apenas alguns anos. Por essa razão a edição do Polímeta de Morhof de 1747 (um guia que era constantemente revisto e ampliado) começava com uma lista em ordem alfabética das revistas dessa natureza.

Às bibliografias logo se juntaram estantes de outros livros de referência. Tinham títulos tais como "castelo", "compêndio", "corpus", "catálogo", "flo- 
resta”, “inventário", biblioteca”, “espelho”, "repertório", “teatro” ou "tesouro", e ofereciam informações sobre palavras (dicionários), pessoas (dicionários biográficos), lugares (dicionários geográficos e atlas), datas (cronologias) e coisas (enciclopédias). Havia também coleções de muitos volumes de textos sobre tópicos específicos - leis, tratados, crônicas, decisões de concílios da Igreja, descrições de lugares exóticos feitas por viajantes etc. Em 1758 apareceu até um dicionário de dicionários, publicado em Paris e ridicularizado pelo literato exilado Melchior Grimm mas que mesmo assim satisfazia a uma necessidade real. Era o livro Table alphabéthique des dictionnaires de Durey de Noinville.

Esses livros não se destinavam apenas a estudiosos e grupos com interesses específicos mas também a pessoas que liam o jornal (daí os termos gazzetteer (jornalista de diário oficial) e Konversationslexikon). O aparecimento desse tipo de livros foi incrementado não só pelo aumento da informação, mas também pela competição. A comercialização do conhecimento já era visível na época de Gutenberg, como testemunham os volantes comerciais que anunciavam libri venales (livros à venda). Todavia, a comercialização deu um grande passo para a frente no século XVIII, participando do surgimento da "sociedade de consumo" na Inglaterra, na França, na Alemanha e em outros países por volta de $1750(15)$.

Todas essas soluções de problemas criaram outros problemas e provocaram grandes mudanças nos estilos de leitura, escrita e organização de informações.

Escrevendo em 1819, Francis Jeffrey, um literato inglês, expressava seu temor de que "se continuarmos a escrever e rimar no ritmo atual por mais 200 anos, será preciso inventar alguma nova arte de leitura taquigráfica - caso contrário toda leitura será abandonada em desespero" (16). De um modo informal, era o que já vinha acontecendo havia séculos. Houve uma mudanças da leitura "intensiva" para a "extensiva" (ou, na famosa metáfora de Francis Bacon, do hábito de "engolir" livros para o de "provar" deles). O final do século XVIII tem sido apresentado como um ponto crucial nesse aspecto (embora não se deva esquecer que os primeiros homens modernos, como nós mesmos, sabiam mudar de marcha e passar de uma modalidade de leitura para outra quando necessário) (17). Um novo vocabulário entrou em uso no início do período moderno para descrever essa "revolução na leitura", incluindo-se palavras como "referir-se", "consultar", "ler superficialmente" e "pular". Como comentava Jonathan Swift com seu costumeiro humor pessimista, "entrar no palácio do conhecimento pelo portão principal exige um consumo de tempo e formalidades. Gente muito apressada e pouco cerimoniosa se contenta com entrar pela porta dos fundos". Essas formas de leitura equivaliam a "surfar pela internet".

A modalidade de leitura "extensiva" estimulou mudanças no formato e na apresentação dos livros e foi por sua vez por elas estimulada. Ocorreram mu- 
danças como a divisão do texto em capítulos, o acréscimo de sumários, índices (incluindo-se alguns índices de máximas assim como de assuntos ou de nomes de pessoas e lugares) e notas marginais indicando mudanças de tópicos. Houve uma considerável competição entre editores nessas questões. Os títulos das páginas com freqüência referiam-se ao número e à precisão dos índices, glossários e assim por diante para motivar a compra de uma edição específica de um texto clássico (18).

Foi o que aconteceu, por exemplo, com as cerca de cem edições do famoso Cortesão de Baldassare Castiglione, publicado pela primeira vez em italiano no ano 1528. Sucessivas edições foram acrescentando ao texto uma divisão em capítulos, além de sumário, índice e notas marginais. Um editor plagiou o índice de um concorrente, mas esqueceu que os números das páginas já não eram adequados para sua edição. Uma das conseqüências mais sérias desse aparato de acréscimos ou "paratexto" foi a mudança da mensagem do livro, que o transformou de um diálogo aberto que questiona regras de conduta em um livro que ensina como se comportar. $\mathrm{O}$ paratexto tornou-se um sistema auto-referente. $\mathrm{O}$ índice, por exemplo, baseava-se nas observações marginais e não mais no texto, e incluía orientações como "O cortesão deve saber dançar" (19). Não devemos subestimar o poder do formato na definição de percepções e expectativas, o Erwartungshorizont dos leitores.

Mudanças também ocorreram na maneira de escrever: especificamente, surgiu a "nota de rodapé", fenômeno típico do século XVIII, analisado num recente ensaio erudito e elegante de Anthony Grafton (20). Não se deve tomar muito literalmente o termo "nota de rodapé". O que aconteceu de importante foi a difusão da prática erudita de providenciar algum tipo de orientação para o leitor de um determinado texto: onde encontrar provas e informação adicional, podendo essa orientação aparecer no próprio texto, na margem ("nota lateral"), no pé da página ("notas inferiores"), no fim do texto ou em apêndices especiais contendo documentos.

A idéia principal dessas novas práticas era facilitar a volta às "fontes", com base no princípio de que a informação, como a água, era tanto mais pura quanto mais perto chegava da nascente. A nota histórica, como a descrição detalhada de uma experiência, tinha o intuito de permitir que o leitor repetisse a experiência se assim lhe aprouvesse.

A volta às fontes (ad fontes) foi um lema dos humanistas da Renascença bem como dos reformadores protestantes. Alguns historiadores do século XVI tiveram o cuidado de referir-se aos manuscritos em que baseavam seus relatos do passado. Como prática comum, todavia, a nota de rodapé remonta ao século XVII. No século XVIII alguns leitores estavam habituados a contar com ela, como testemunha a queixa de Horace Walpole a David Hume em 1758 a respeito da ausência de "referências nas margens" de sua obra History of England. 
Hume admitiu em sua resposta que a prática de apresentar referências "uma vez introduzida, deveria ser observada por todos os escritores". Um novo código de conduta erudita fora estabelecido. Hoje, sem dúvida, precisamos de um código de conduta semelhante para a internet.

Finalmente, houve mudanças na organização da informação, especialmente com o surgimento da ordem alfabética em substituição à organização por assunto. A idéia da ordem alfabética não era nova (já fora empregada no século XI na enciclopédia bizantina conhecida como Suidas). A inovação agora era a abrangência dessa modalidade de organização e a forma como veio a suplantar classificações mais hierárquicas. Até o final do século XVII, a organização por ordem alfabética era bastante rara, a ponto de o editor de um livro de referência sobre o mundo muçulmano (Bibliothèque orientale de Herbelot) julgar necessário antecipar suas escusas, declarando que seu método "não provoca tanta confusão como se poderia imaginar". De qualquer maneira, houve uma mudança a longo prazo a partir das enciclopédias do século XVI, como a Margarita Philosophica de Gregor Reisch, que foi organizada como o currículo das universidades e podia ser lida do início até o fim, até as enciclopédias do século XVIII organizadas em ordem alfabética para facilitar a consulta, o que virtualmente impossibilitava sua leitura do princípio ao fim.

As novas modalidades de leitura, escrita e organização da informação provocaram por sua vez suas próprias conseqüências imprevistas, tanto no campo social quanto no intelectual.

Uma das conseqüências sociais da organização da informação foi o surgimento de novas ocupações. A imprensa trouxe consigo não apenas um novo grupo social de editores, mas também aliou ocupações tais como a de revisor e bibliotecário. A eles se juntaram, nos séculos XVII e XVIII, na execução da tarefa de administrar materiais impressos, indexadores, editores e catalogadores profissionais ou semiprofissionais e compiladores de enciclopédias. Ainda era possível para um indivíduo compilar uma enciclopédia, como fez Pierre Bayle no fim do século XVII, ou Ephraim Chambers no início do XVIII. Todavia, a nova tendência era trabalhar em equipe, como no famoso caso da Encyclopédie ou, um pouco antes, no empreendimento do editor alemão Johann Heinrich Zedler de Leipzig. A enciclopédia de Zedler, Grosses Voolständiges Universal-Lexicon aller Künste und Wissenschaften, publicada em 64 volumes in-folio (duas colunas por página) entre 1732 e 1754, resultou dos esforços de nove colaboradores eruditos e (a partir do volume 19) um editor em tempo integral, Carl Günther Ludovici, que cuidava de problemas técnicos, entre eles a remissão recíproca (21). Em outras palavras, as novas enciclopédias ampliadas dependiam de uma diversidade profissional que era maior, do ponto de vista social e intelectual, do que a de seus predecessores. 


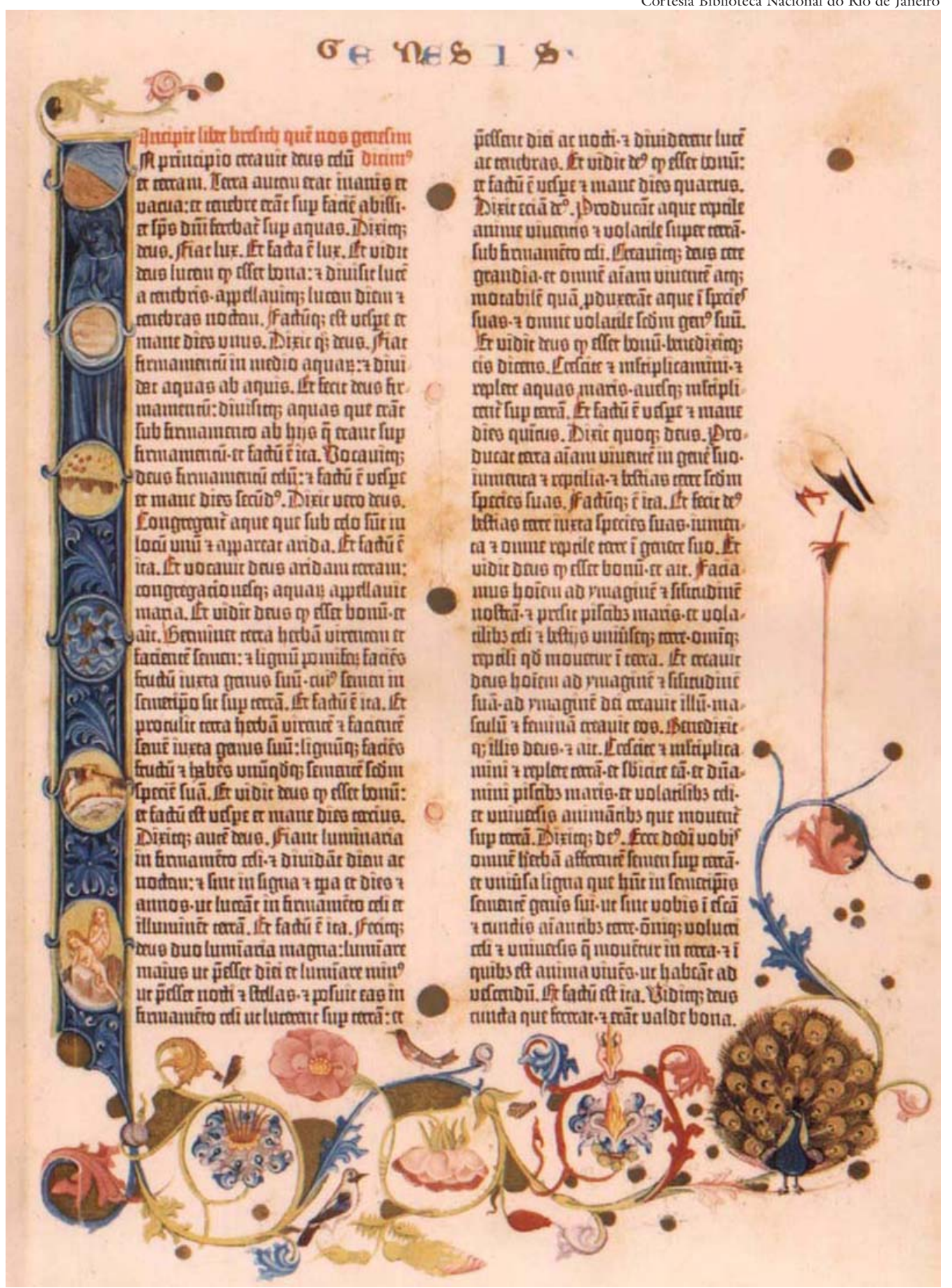

Página do Genesis da Bíblia de Mogúncia - de que a Biblioteca Nacional do Rio de Janeiro possui um exemplar em pergaminho -, impressa em 1462 por Schoeffer e não por Gutenberg. 
A divisão do trabalho intelectual não se limitou a enciclopédias. Houve uma tendência geral para a especialização e fragmentação em detrimento do ideal geral do conhecimento. O surgimento da historia literária sugere que houve um deslocamento de objetivos: o mundo dos livros estava se tornando um objeto de estudo em si mesmo mais do que um meio de entender o mundo em sua amplitude. Bacon, como vimos, havia associado a imprensa com a pansofia. A trágica ironia foi que o surgimento da imprensa tornou esse ideal cada vez mais irrealista.

O escritor religioso Richard Baxter já observava a respeito da crescente fragmentação do conhecimento em seu Holy Commonwealth (1659): "Dividimos artes e ciências em fragmentos, de acordo com as limitações de nossas capacidades, e não somos tão pansóficos a ponto de uno intuitu enxergarmos o todo". Talvez tenha ocorrido um avanço do conhecimento no nível coletivo, no sentido de que foram feitas novas descobertas e de que mais informação foi disponibilizada em materiais impressos. Mas no nível do indivíduo houve uma séria perda.

É difícil dizer quem foi o último polímeta, mas pelo final do século XVII era evidente que essa espécie estava ameaçada. O estudioso inglês Meric Casaubon (filho de Isaac Casaubon, que era mais conhecido) escreveu uma apologia do que ele chamava de "conhecimentos gerais" em meados do século XVII, mas o tratado permaneceu no prelo até o final do século XX (22).

Leibniz conseguiu fazer contribuições originais em campos tão diversos como matemática e história, sem mencionar biblioteconomia. Todavia, alguns de seus mais famosos colegas do século XVII - como Jan Amos Comenius, Athanasius Kircher e Olaus Rudbeck - estiveram à beira da excentricidade, se é que não caíram nela, como se apenas a obsessão pelo estudo pudesse buscar o ideal da pansofia numa época em que os obstáculos práticos se tornavam cada vez maiores e mais óbvios do que antes.

O autor do artigo sobre gens de lettres da Encyclopédie estava mais resignado, declarando que "o conhecimento universal já não está ao alcance do homem" (la science universelle n'est plus à la portée de l'homme). Tudo o que se poderia fazer nas novas circunstâncias era tentar evitar a mesquinhez intelectual pelo incentivo ao "espírito filosófico", estabelecendo conexões e extraindo as implicações mais amplas de estudos especializados. Esse conselho continua absolutamente pertinente para nós hoje.

Notas

1 Entre os mais importantes, L. Febvre \& H.-J. Martin, L'apparition du livre (Paris, 1958), e E. Eisenstein, The printing press as an agent of change (2 v., Cambridge, 1979). 
2 T. Hägerstrand, Some unexplored problems in the modeling of culture transfer and transformation, in P.J. Hugill \& D.B. Dickson (eds.) The transfer and transformation of ideas and material culture (College Station, Texas, 1988), p. 217-232.

3 Discutido em M. Giesecke, Der Buchdruck in der frühen Nenzeit (1991, 2 $2^{\text {nd }}$. ed. Frankfurt 1998), p. 168 e ss.

4 M. Lowry, The world of Aldus Manutius (Oxford, 1979), p. 24-41; B. Richardson (1998) The debates on printing in Renaissance Italy, La Bibliofilia 100, p. 135-55.

5 L. Davidico, citado em G. Fragnito, La Bibbia al rogo: la censura ecclesiastica e I volgarizzamenti della Scrittura: 1471-1605 (Bologna, 1997), p. 73.

6 E. Johansson, The history of literacy in Sweden (1977: reproduzido em H.J. Graff (ed.), Literacy and social development in the West (Cambridge 1981), p. 151-182.

7 G. Kitchin, Sir Roger l'Estrange (London, 1913).

8 E.C. Tennant, The protection of invention: printing privileges in early Modern Germany, in G.S. Williams \& S.K. Schindler (eds.) Knowledge, science and literature in early Modern Germany (Chapel Hill, 1996) p.7-48, em especial p.9.

9 Citado em G. Cavallo \& R. Chartier (eds.) A history of reading in the West (Cambrige, 1999), p. 234.

10 Basnage, citado em H.H.M. van Lieshout, Dictionnaires et diffusion de savoir, in H. Bots \& F. Waquet (eds.), Commercium litterarium (Amsterdam and Maarssen, 1994), p. 134.

11 A. Baillet, Jugements des savants sur les principaux ouvrages des anciens (4 v., Paris, 1685-1686), prefácio.

12 R. Chartier, L'ordre des livres (Aix-en-Provence, 1992).

13 A. Serrai, Conrad Gessner (ed.) M. Cochetti (Rome, 1990); H. Zedelmaier, Bibliotheca Universalis und Bibliotheca Selecta: Das problem der Ordnung des gelehrten Wissens in der frühen Neuzeit (Cologne, 1992), p. 3-153.

14 E. Canone, Bibliothecae selectae da Cusano a Leopardi (Florence, 1993); Zedelmaier (1992).

15 N. McKendrick, J. Brewer \& J.H. Plumb, The birth of a consumer society (London, 1982); R. Sandgruber, Die Anfänge der Konsumgesellschaft (Vienna, 1982); J. Brewer \& R. Porter (eds.), Consumption and the world of goods (London, 1993); D. Roche, Histoire des choses banales (Paris, 1997).

16 Citado em M. Phillips, Society and sentiment: genres of historical writing in Britain, 1740-1820 (Princeton, 2000), p. 294.

$17 \mathrm{R}$. Witmann, Was there a reading revolution at the end of the eighteenth century?" in Cavallo \& Chartier, p. 284-312.

18 B. Richardson, Print culture in Renaissance Italy: the editor and the vernacular text, 1470-1600 (Cambridge, 1994).

19 P. Burke, The fortunes of the courtier (Cambridge, 1995), p. 42-44, 73-75.

20 A. Grafton, The footnote: a curious history (London, 1997). 
21 P.E. Carels \& D. Flory, J. H. Zedler's Universal Lexicon, in F.A. Kafker (ed.), Notable Encyclopaedias (Oxford, 1981), p. 165-195.

22 M. Casaubon, General learning, R. Serjeantson editor (London, 1999).

Peter Burke, historiador, é professor do Emmanuel College Cambridge (Inglaterra).

Este artigo é uma versão revista de uma palestra feita pelo autor em Mainz (Alemanha) em junho de 2000. Nele são utilizados material discutido, detalhes e notas de rodapé mais extensas de livro a ser publicado, A social history of knowledge from Gutenberg to Diderot (Cambridge, 2000). Ver também A. Briggs \& P. Burke, A social history of the midia (Cambridge, 2000).

Tradução de Almiro Piseta. O original em inglês - Coping with Gutenberg: the information explosion in early modern Europe - encontra-se à disposição do leitor no IEA-USP para eventual consulta. 